\title{
70. Using PERFORM .. VARYING
}

While carrying out a repetitive task, it is often useful to be able to keep count of how many times it is carried out. This can be done using PERFORM .. VARYING.

\section{Example}

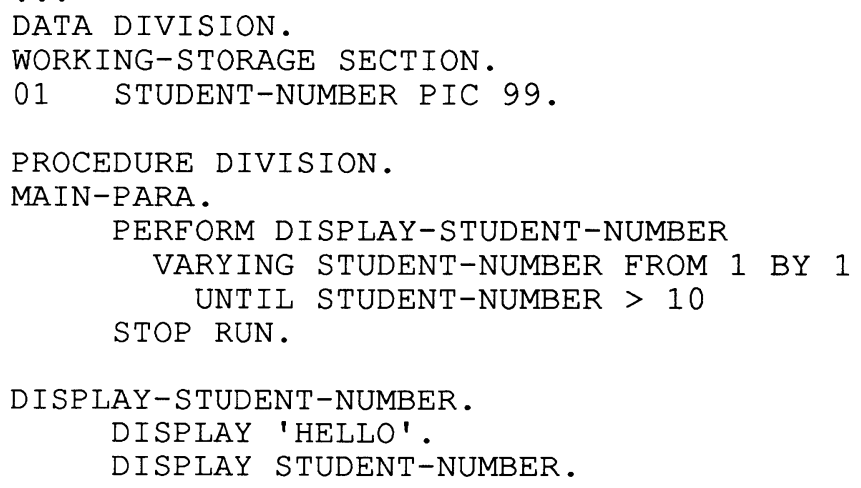

Ensure that the data item which will contain the count is big enough to hold the largest number in the sequence.

Note that you can alter the starting point for the count and the jumps in the count by altering the FROM and BY values - e.g.

\section{PERFORM DISPLAY-STUDENT-NUMBER \\ VARYING STUDENT-NUMBER FROM 10 BY 5 UNTIL STUDENT-NUMBER $>50$.}

This would start the student-number off at 10 and increase it to 15 , then to 20 and so on until after it had reached 50.

\section{Exercises}

1. Write a program which will display all the whole numbers from 1 to 100 .

2. Write a program which will display the numbers between 20 and 50 in intervals of 2 . 